\title{
Long-term treatment effect and adverse events of a modified jailed-balloon technique for side branch protection in patients with coronary bifurcation lesions
}

\author{
Wenduo Zhang, Fusui Ji ${ }^{*} \mathbb{D}$, Xue Yu and Xinyue Wang
}

\begin{abstract}
Background: Percutaneous coronary interventions (PCI) of bifurcation lesions is technically challenging and associated with lower success rates and higher frequency of adverse outcomes. In the present study, we aimed to evaluate the immediate and long-term treatment effect and adverse events of a new modified jailed-balloon technique on side branch (SB) during $\mathrm{PCl}$ on coronary bifurcation lesions.

Methods: This was a prospective study of 60 patients (49 males, 11 females, mean age $66 \pm 10$ years) with coronary bifurcation lesions treated at the Beijing Hospital between September 2014 and October 2015. They underwent main vessel (MV) stenting and modified jailed-balloon technique on the SB. All patients were followed with hospital visits at 9 months. Angiographic success, major adverse cardiac events (MACE), SB occlusion, and angina were evaluated.

Results: The majority of the patients had acute coronary syndrome (91.7\%) and Medina 1.1.1. bifurcation lesions (71.7\%). After MV stenting, thrombolysis in myocardial infarction (TIMI) 3 flow was established 100\% of MV and 93. $3 \%$ of SB. No SB occlusion occurred. The jailed SB balloon and wire could be successfully removed in all patients without damage or entrapment. The majority (91.7\%) of patients achieved Canadian Cardiovascular Society I stage. There was no MACE during in-hospital stay and 9-month follow-up.
\end{abstract}

Conclusion: The modified JBT provided high rate of procedural success, excellent SB protection during MV stenting, and excellent immediate and long-term clinical outcomes.

Keywords: Percutaneous coronary intervention, Modified jailed balloon technique, Coronary bifurcation lesions, Long-term

\section{Introduction}

Acute coronary syndromes (ACS) refer to a spectrum of acute myocardial ischemia and/or necrosis usually secondary to reduction in coronary blood flow and include unstable angina, non-ST-elevation myocardial infarction, and ST-elevation myocardial infarction [1,2]. The incidence of ACS is approximately 1 million cases in the United Stated and 2 million in Europe [2]. Due to the rapid economic development of the Asia-Pacific region, including China, $<50 \%$ of the adults meet the NCEP-ATPIII low-density

\footnotetext{
* Correspondence: jifusui@126.com

Department of Cardiology, National Center of Gerontology, China, Beijing Hospital, NO.1 DaHua Road, Dong Dan, Beijing 100730, People's Republic of China
}

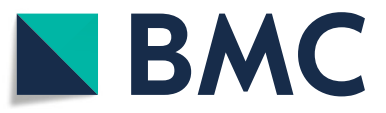

(c) The Author(s). 2019 Open Access This article is distributed under the terms of the Creative Commons Attribution 4.0 International License (http://creativecommons.org/licenses/by/4.0/), which permits unrestricted use, distribution, and reproduction in any medium, provided you give appropriate credit to the original author(s) and the source, provide a link to the Creative Commons license, and indicate if changes were made. The Creative Commons Public Domain Dedication waiver (http://creativecommons.org/publicdomain/zero/1.0/) applies to the data made available in this article, unless otherwise stated.

lipoprotein cholesterol levels [3, 4], resulting in significant mortality and morbidity $[5,6]$.

Atherosclerosis development involves the interplay of cardiovascular risk factors, inflammation, vascular biology and local hemodynamics [7]. Vascular geometries characterized by changes in lumen size predispose to plaque development [7]. Artery bifurcations are prone to develop atherosclerosis lesions because of the high shear stress and endothelial erosion from the turbulent blood flow $[8,9]$.

Approximately 15 to $20 \%$ of percutaneous coronary interventions $(\mathrm{PCI})$ are performed to treat coronary bifurcation lesions $[10,11]$. PCI of bifurcation lesions is technically challenging and associated with lower 
success rates and higher frequency of immediate and long-term adverse outcomes $[12,13]$. Despite randomized studies and observational series, the selection of the optimal interventional strategy for true coronary bifurcation lesions remains controversial because of the variability in side branch (SB) disease and the desire to preserve the patency of the SB $[14,15]$.

According to previous studies, the one-stent strategy with provisional SB stenting is superior to the elective two-stent strategy and considered as the first option for most coronary bifurcation lesions [16, 17]. A modification of the provisional stenting strategy called the jailed-balloon technique (JBT) is designed to reduce SB occlusion during main vessel (MV) stenting, but cannot fully prevent it $[18,19]$.

Therefore, the aim of the present study was to explore the immediate and long-term treatment effect and adverse events of a new modified JBT for SB protection during PCI on coronary bifurcation lesions. This new technique could improve the prognosis of patients with bifurcation lesions treated with PCI.

\section{Materrials and methods}

\section{Study design and patients}

This was a prospective study of patients with coronary bifurcation lesions treated at the Beijing Hospital between September 2014 and October 2015. Each coronary bifurcation lesion was classified according to the Medina classification [20]. The study was approved by the Ethics Committee of Beijing hospital. Written informed consents for both the PCI procedure and participation in the study were obtained from all patients.

True bifurcation lesion, defined as a stenosis $>50 \%$ in both the MV and the ostium of the SB and Medina
1.1.1., Medina 1.0.1., Medina 0.1.1. bifurcation lesions, were included [21]. The vessel size was analyzed by quantitative coronary angiography (QCA). Patients with heavily calcified lesions, severe proximal tortuosity, cardiogenic shock, or contraindications to prolonged use of antiplatelet agents were excluded.

\section{Data collection}

After collecting the detailed medical history and performing a complete physical examination, the baseline characteristics of the patients (including age, gender, hypertension, hypercholesterolemia, diabetes mellitus, current smoking status, and medications) were recorded.

\section{Pre-operative management}

All patients received aspirin $(300 \mathrm{mg}$ ) and a loading dose of clopidogrel $(300 \mathrm{mg}$ ) prior to or at the time of selective PCI. During the procedure, an intra-arterial bolus of unfractionated heparin (UFH) was administered at $70-100 \mathrm{U} / \mathrm{kg}[22]$.

\section{Procedure}

For the modified JBT, $6 \mathrm{Fr}$ guiding catheters were used via a transradial approach. The procedure is illustrated in Fig. 1. The procedure started with the wiring of both branches (Fig. 1a). The MV lesion was managed with a standard semi-compliant balloon predilatation (Fig. 1b). A stent with adequate size and length was used to cover the MV lesion, then a fitful balloon was sent into the SB; the proximal markers of the SB balloon were not beyond that of the MV stent, and the distal markers covered the SB ostium lesion (Fig. 1c). The MV stent balloon and SB balloon were inflated simultaneously; the SB balloon was inflated to the normal pressure, then both balloon were deflated together
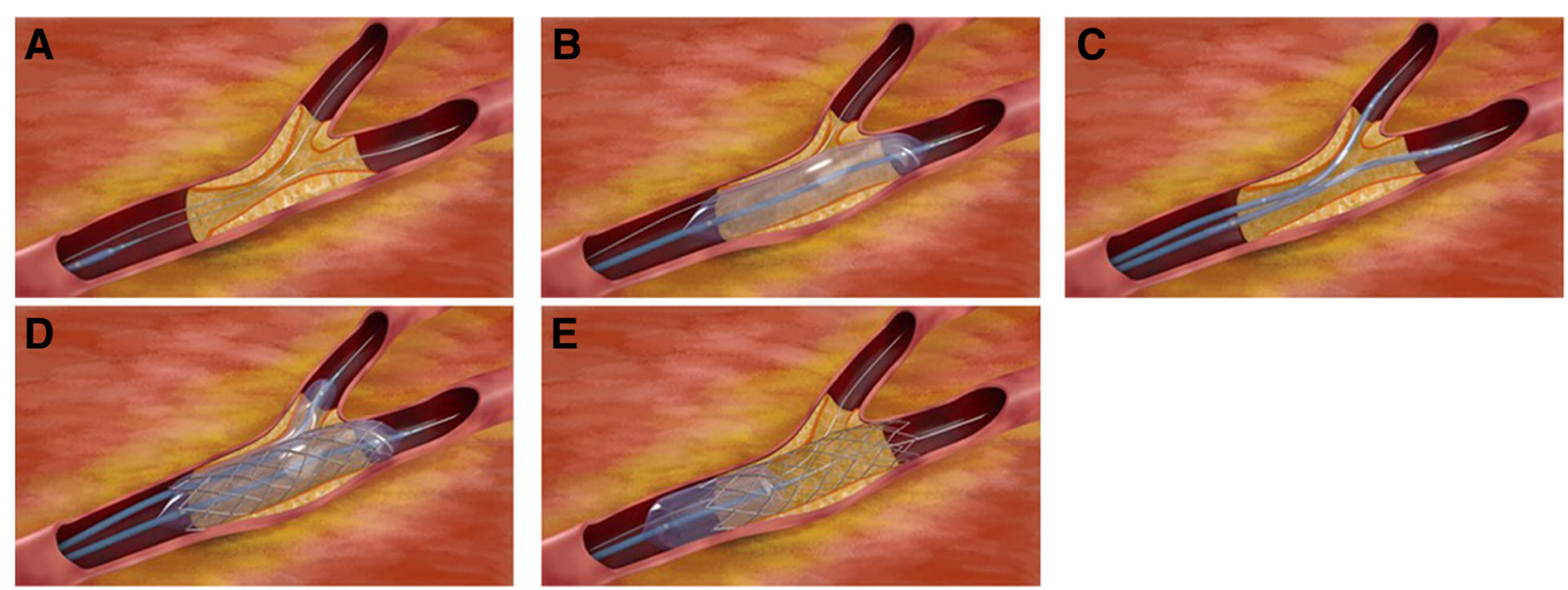

Fig. 1 The new modified jailed-balloon technique. a The procedure starts with the wiring of both branches. $\mathbf{b}$ A standard POBA for the main vessel (MV) lesion. c The stent is sent to cover the MV lesion, then a balloon is sent into the side branch (SB). The proximal markers of the SB balloon were not beyond those of the MV stent. $\mathbf{d}$ The MV stent balloon and SB balloon were inflated simultaneously. The SB balloon was inflated to its normal pressure. Both balloon were deflated together and removed. e The MV stent was inflated with appropriate balloon pressures again 
and removed (Fig. 1d). For optimization of MV stent apposition, the proximal optimization technique (POT) was performed with a short non-compliant balloon (Fig. 1e); if the SB diameter was over $2.5 \mathrm{~mm}$, POT was not performed, but the wires of MV and SB were exchanged, and the procedure was completed with final kissing.

\section{Postoperative management}

Following PCI, all patients were monitored for post-procedural complications. Cardiac troponins and creative kinase-MB were measured before the procedure and 12$18 \mathrm{~h}$ post-intervention. Marker elevation $\geq 3$ times the upper limit of normal was considered significant. For patients who already had elevated cardiac enzyme levels before the procedure, marker elevation $\geq 50 \%$ that of the previous value was considered significant [23]. All patients were discharged following PCI with dual antiplatelet therapy (aspirin $100 \mathrm{mg} / \mathrm{d}$ and clopidogrel $75 \mathrm{mg} / \mathrm{d}$ ) and followed with hospital visits for 9 months.

\section{Definitions and outcomes}

Procedural and immediate clinical outcomes were recorded. Angiographic success was defined as successful implantation of the stent into the MV and final residual stenosis $\geq 30 \%$ without MV and SB flow impairment [19]. Clinical events were defined based on the recommendations of the Academic Research Consortium [23]. Major adverse cardiac events (MACE) were defined as a composite of cardiac death, myocardial infarction (MI), or target lesion revascularization (TLR). Thrombolysis in myocardial infarction (TIMI) flow grading was established for the MV and SB for each patient. SB occlusion was defined as the absence of flow in the SB immediately following MV stenting [24]. Angina was graded according to the angina classification of Canadian Cardiovascular Society (CCS) [25].

\section{QCA analysis}

QCA analyses were performed for the MV and SB at baseline, after stent implantation, and at 9 months using the QAngio7.2 QCA software (Medis Medical Imaging System Inc., Leiden, The Netherlands). All analyses were performed in consensus by two experienced interventional cardiologists who were blinded to the patients' characteristics. The QCA of each bifurcation lesion was obtained for the MV and SB. For quantitative analysis, at least two orthogonal projections were obtained. Angiographic frames with homogeneous contrast filling of the segment of interest were selected in a view offering good opening of the bifurcation. According to the algorithm in the dedicated software, reference vessel diameter, minimal lumen diameter, and diameter stenosis were measured in two segments.

\section{Statistical analysis}

All calculations were performed with SPSS 17.0 (IBM, Armonk, NY, USA). Continuous variables were expressed as mean \pm standard deviation (SD) and categorical variables were presented as frequency and percentage. Pre- and post-procedure QCA results were compared using the paired sample t-test or McNemar's test, as appropriate. Two-sided $P$-values $<0.05$ were considered significant.

\section{Results and discussion \\ Characteristics of the patients}

The $60(100 \%)$ patients successfully underwent the modified JBT and were included in final analysis. The baseline clinical characteristics of the patients are shown in Table 1 . The patients were $66 \pm 10$ years of age and $81.7 \%$ were male. Most patients (91.7\%) were admitted to hospital with ACS and 58.3\% patients had diabetes mellitus. Ten patients had a history of PCI.

\section{Characteristics of the lesions}

Table 2 shows that all the patients were operated using the transradial approach and six Fr guiding catheters. The lesions were in the distal left main (LM) coronary artery in eight patients (13.3\%), the left anterior descending artery (LAD)-diagonal branch (D) level in $48(80.0 \%)$, the left circumflex artery (LCX)-obtuse marginal branch $(\mathrm{OM})$ level in one (1.7\%), and the right coronary artery (RCA) posterior descending artery (PD)-posterolateral artery (PL) level in three (5.0\%). Forty-three (71.7\%) patients had Medina type 1.1.1 lesion. Rates of pretreatment TIMI 3 flow in MV and SB were in 100 and 78.3\%, respectively. Predilatation of MV and SB was performed in 100 and $0 \%$ lesions, respectively. All implanted stents were secondgeneration drug eluting stent.

Table 1 Baseline characteristics of the patients

\begin{tabular}{ll}
\hline Variable & Patients $(n=60)$ \\
\hline Age (years), mean \pm SD & $66 \pm 10$ \\
Gender, $\mathrm{n}(\%)$ & \\
$\quad$ Male & $49(81.7)$ \\
$\quad$ Female & $11(18.3)$ \\
Diabetes, n (\%) & $35(58.3)$ \\
Hypertension, n (\%) & $49(81.7)$ \\
Smoking, n (\%) & $36(45.0)$ \\
Hypercholesterolemia, n (\%) & $46(76.7)$ \\
Prior PCl, n (\%) & $10(16.7)$ \\
Prior by-pass surgery, n (\%) & $1(1.67)$ \\
PCl indication, $\mathrm{n}(\%)$ & \\
Stable angina & $5(8.3)$ \\
Non-ST acute coronary syndrome & $55(91.7)$ \\
\hline
\end{tabular}

$\overline{P C l}$, percutaneous coronary intervention 
Table 2 Angiographic and procedural characteristics

\begin{tabular}{|c|c|}
\hline Variable & Patients $(n=60)$ \\
\hline \multicolumn{2}{|l|}{ Lesion location, n (\%) } \\
\hline LM\LAD\LCX & $8(13.3)$ \\
\hline$L A D \backslash D$ & $48(80.0)$ \\
\hline LCXIOM & $1(1.7)$ \\
\hline RCA $P D$ or $P L$ & $3(5.0)$ \\
\hline \multicolumn{2}{|l|}{ Medina type, n (\%) } \\
\hline 1.1.1 & $43(71.7)$ \\
\hline 1.0 .1 & $7(11.7)$ \\
\hline 0.1 .1 & $10(16.7)$ \\
\hline \multicolumn{2}{|c|}{ MV pretreatment TIMI flow, n (\%) } \\
\hline $0-1$ & 0 \\
\hline 2 & 0 \\
\hline 3 & $60(100)$ \\
\hline \multicolumn{2}{|c|}{ SB pretreatment TIMI flow, n (\%) } \\
\hline $0-1$ & $1(1.7)$ \\
\hline 2 & $12(20.0)$ \\
\hline 3 & $47(78.3)$ \\
\hline Transradial approach, n (\%) & $60(100)$ \\
\hline \multicolumn{2}{|l|}{ Predilatation, n (\%) } \\
\hline MV & $60(100)$ \\
\hline SB & 0 \\
\hline \multicolumn{2}{|l|}{$\mathrm{MV}$ size $(\mathrm{mm})$, mean $\pm \mathrm{SD}$} \\
\hline Diameter & $3.18 \pm 0.44$ \\
\hline Length & $22.52 \pm 7.82$ \\
\hline \multicolumn{2}{|l|}{$\mathrm{SB}$ size $(\mathrm{mm})$, mean $\pm \mathrm{SD}$} \\
\hline Diameter & $2.11 \pm 0.41$ \\
\hline Length & $10.03 \pm 4.41$ \\
\hline
\end{tabular}

$L M$, left main coronary artery; $L A D$, left anterior descending artery; $D$, diagonal branch; $L C X$, left circumflex branch; $O M$, obtuse marginal branch; $R C A$, right coronary artery; $P D$, posterior descending artery; $P L$, posterolateral branch; $S B$, side branch; $M V$, main vessel

\section{Outcomes}

Immediate procedural, post-procedural, and 9-month outcomes are shown in Table 3. The procedural success rate was $100 \%$. After MV stenting, there was no SB loss and all patients had TIMI 3 flow in the MV. In only one $(1.7 \%)$ patient the SB remained TIMI 1 flow compared with pre-procedure. Three patients were with TIMI 2 flow due to long- and high-grade stenosis at SB ostium after MV stenting. After giving nitroglycerin in the coronary artery, coronary flow reached TIMI 3 flow in two patients. Therefore, the final kissing balloon inflation was performed in only one patient. No patient needed additional stent due to proximal or distal stent edge dissection. The jailed SB balloon and wire could be successfully removed in all patients without damage or entrapment. The peri-procedural MI rate was $0 \%$
Table 3 Initial procedural and clinical outcomes

\begin{tabular}{|c|c|c|}
\hline Variable & $\begin{array}{l}\text { Post-procedur } \\
(n=60)\end{array}$ & $\begin{array}{l}\text { After } 9 \text { months } \\
(n=60)\end{array}$ \\
\hline Procedural success, n (\%) & $60(100)$ & NA \\
\hline Peri-procedural MI, n (\%) & 0 & 0 \\
\hline SB loss, n (\%) & 0 & 0 \\
\hline \multicolumn{3}{|l|}{ MV TIMI flow after MV stenting, n (\%) } \\
\hline 0 & 0 & 0 \\
\hline 1 & 0 & 0 \\
\hline 2 & 0 & 0 \\
\hline 3 & $60(100)$ & $60(100)$ \\
\hline \multicolumn{3}{|l|}{ SB TIMI flow after MV stenting, n (\%) } \\
\hline 0 & 0 & 0 \\
\hline 1 & $1(1.7)$ & 0 \\
\hline 2 & $3(5.0)$ & 0 \\
\hline 3 & $56(93.3)$ & $60(100)$ \\
\hline SB dissection, n (\%) & 0 & 0 \\
\hline SB stenting, n (\%) & 0 & 0 \\
\hline Final kissing balloon inflation, n (\%) & $1(1.7)$ & NA \\
\hline Death, n (\%) & 0 & 0 \\
\hline MI, n (\%) & 0 & 0 \\
\hline Repeat $\mathrm{PCl}$ or $\mathrm{CABG}, \mathrm{n}(\%)$ & 0 & 0 \\
\hline \multicolumn{3}{|l|}{ CCS, n (\%) } \\
\hline । & NA & $55(91.7)$ \\
\hline$\|$ & NA & $5(8.3)$ \\
\hline III-IV & NA & 0 \\
\hline
\end{tabular}

$S B$, side branch; $T I M I$, thrombolysis in myocardial infarction; $M V$, main vessel; $M I$, myocardial infarction; $N A$, not applicable; $P C l$, percutaneous coronary intervention; $C A B G$, coronary artery bypass graft; $C C S$, Canadian Cardiovascular Society

and there was no MACE during in-hospital stay and 9-month follow-up. The majority (91.7\%) of patients achieved CCS I stage. No patient's symptoms exacerbated to CCS III-IV stage.

QCA

QCA results for both the MV and SB at baseline, after procedure, and after 9 months are shown in Table 4 . The mean post-procedure minimum lumen diameter in $\mathrm{MV}$ and SB were $2.79 \pm 0.45 \mathrm{~mm}$ and $0.84 \pm 0.59 \mathrm{~mm}$, respectively. Compared with baseline, there was significant difference in post-procedure and after 9 months in MV $(P<0.001)$. Although only $93.3 \%$ patients achieved TIMI 3 flow post-procedure, all patients achieved TIMI 3 flow at 9 months $(\mathrm{P}<0.001$ vs. post-procedure).

\section{Results and discussion}

PCI of bifurcation lesions is technically challenging and associated with lower success rates and higher frequency of adverse outcomes. The objective of the 
Table 4 Quantitative coronary angiographic analysis

\begin{tabular}{|c|c|c|c|}
\hline Variable & Baseline $(n=60)$ & Post procedure $(n=60)$ & After 9 months $(n=60)$ \\
\hline \multicolumn{4}{|l|}{ Main vessel, mean \pm SD } \\
\hline MLD (mm) & $1.16 \pm 0.41$ & $2.79 \pm 0.45^{\&}$ & $2.67 \pm 0.32^{\&}$ \\
\hline Diameter stenosis (\%) & $50.98 \pm 12.97$ & $12.06 \pm 6.09^{\&}$ & $10.62 \pm 6.767^{\&}$ \\
\hline \multicolumn{4}{|l|}{ Side branch, mean \pm SD } \\
\hline MLD (mm) & $0.83 \pm 0.59$ & $0.84 \pm 0.59$ & $0.83 \pm 0.67$ \\
\hline Diameter stenosis (\%) & $68.32 \pm 21.02$ & $47.94 \pm 23.82$ & $63.04 \pm 28.23$ \\
\hline TIMI flow 3, n (\%) & $47(78.3)$ & $56(93.3)^{\&}$ & $60(100)^{8 \#}$ \\
\hline
\end{tabular}

$M L D$, minimum lumen diameter; TIMI, thrombolysis in myocardial infarction;

${ }^{\&} P<0.05$ vs. baseline

${ }^{\#} \mathrm{P}<0.05$ vs. post-procedure

present study was to evaluate the immediate and long-term treatment effect and adverse events of a new modified jailed-balloon technique on side branch (SB) during PCI on coronary bifurcation lesions. The results suggest that the modified JBT provided high rate of procedural success, excellent SB protection during MV stenting, and excellent immediate and long-term clinical outcomes.

In our study, the majority of patients presented with ACS (91.7\%) and 71.7\% bifurcation lesion were Medina type 1.1.1. All 60 (100\%) patients successfully underwent this modified JBT. Although there were high clinical and angiographic risks for SB occlusion during MV stenting, we did not observe any SB occlusion post-procedure. Indeed, the advantage of this technique is that acute occlusion of $\mathrm{SB}$ is very unlikely to happen because the $\mathrm{SB}$ balloon is expanded while the stent is inflated, so that the blood vessels on the SB will not show a snow shoveling effect, and the ostium will not be occluded. Hence, the peri-procedural MI rate was $0 \%$ and there was no MACE during in-hospital stay and 9-month follow-up, and most (91.7\%) patients achieved CCS I stage. Depta et al. [26] showed that JBT was associated with a significantly lower rate of MACE compared with no JBT. Therefore, we think that this modified JBT could be better than JBT.

Previously, the jailed guidewire technique has been proven to be effective during the provisional technique [27], and it is nowadays widely adopted in the clinical practice but is also associated with the risk of jailed wire entrapment and does not abolish the risk of SB occlusion. Furthermore, there are several reports of severe complications caused by guidewire fracturing during withdrawal [28]. Burzotta et al. [19] developed the "jailed-balloon technique," a modified provisional method. In this new method, SB was lost after MV stenting in $15 \%$ of patients. Furthermore, they had to implant another stent to SB due to suboptimal outcomes in 50\% of patients. Therefore, the risk of SB occlusion is present after MV stenting due to plaque shift into the
SB [29]. Compaired with original JBT of Burzotta et al.,which SB balloon are only semi-inflated, the main difference of our modified JBT is that SB balloon was inflated to fully normal pressure. By this new modified JBT, the SB ostium stenosis could be adequately reshaped and no patient suffered from TIMI flow 0 in SB.

The major issues about the modified JBT are the possible risk of MV stent struts distortion/malapposition in the MV proximal segment, entrapment of the SB balloon under the MV stent, and SB ostial dissection. As described in the Methods, the proximal markers of the $\mathrm{SB}$ balloon were not beyond that of the MV stent, and the distal markers covered the SB ostium lesion. Because of this, the jailed SB balloon was removed successfully in all patients without damage or entrapment of the balloon, as observed in previous studies [19, 30]. Because the SB balloon is inflated to its nominal pressure, SB ostium stenosis could be adequately reshaped, as in a study by Cayli et al. [31], and no patient suffered from TIMI flow 0 in SB. Good outcomes were also observed in a Japanese study using a modified JBT that is slightly different from ours in the choice of stents [32]. And the good long-term effect was observed in the imaging of many patients in our study and SB Balloon markers(Black arrow) was pointed (Fig. 2).

Although SB TIMI 1 was observed in one patient (1.7\%) and TIMI 2 in three (5\%) patients. In the four cases' with SB blood low flow, the diameter of SB was 2.5-3.0 mm. According to our research experience, SB slow flow happened due to lesion type all Medina 1.1.1, and the serious stenosis(more than 90\%), not by diameter and length of the SB. However, Those patients did not need another stent to $\mathrm{SB}$ and recovered to TIMI 3 in SB at 9 months. That is advantage of this modified JBT technology. By this new modified JBT, the SB ostium stenosis could be adequately reshaped, and it might cause no flow fo more dissection happen by two times dilation of SB. On the other hand, proximal MV stent shape was well inflated. After both inflations, if $\mathrm{SB}>2.5 \mathrm{~mm}$, for optimization of MV stent apposition, 

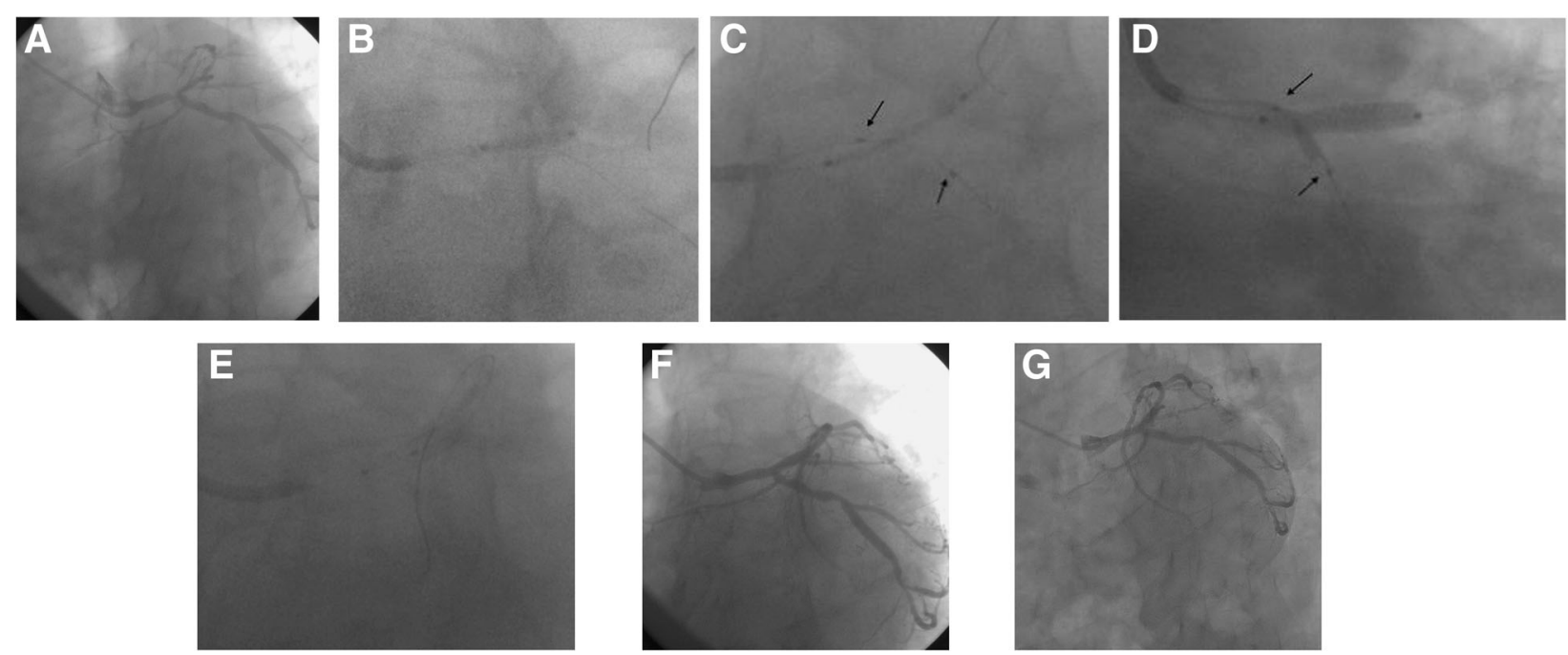

Fig. 2 a Lesion angiography before procedure; (b) The MV lesion was managed with a standard semi-compliant balloon predilatation; (c)A stent with adequate size and length was used to cover the MV lesion, then a fitful balloon was sent into the SB; the proximal markers of the SB balloon were not beyond that of the MV stent(Black Arrow), and the distal markers covered the SB ostium lesion(Black Arrow); (d)The MV stent balloon and SB balloon(Black Arrow)were inflated simultaneously; the SB balloon was inflated to the normal pressure; (e) For optimization of MV stent apposition, the proximal optimization technique (POT) was performed with a short non-compliant balloon; (f)Immediate angiography after operation;(g) 9 months later angiography after operation

the POT was routinely performed with a short noncompliant balloon after removing the jailed balloon. Due to POT, MV stents were well expanded in all patients of the present study. Compared with baseline, the MLD was significantly different after the procedure and after 9 months. All PCI in the present study were performed using $6 \mathrm{Fr}$-guiding catheters via a transradial approach, resulting in less pain after the procedure.

The present study has some limitations. First, the sample size was relatively small. Secondly, the study population was relatively homogenous, characterized by Chinese adults, middle- and old-aged, presenting at a single health Institute. Thirdly, this technique was not compared with other techniques such as traditional provisional technique and JBT. Fourthly, the follow-up was short. Finally, intravascular ultrasound (IVUS) or optical coherence tomography (OCT) were not used in our study. Nevertheless, the present study provides preliminary data for future multicenter randomized controlled trials.

\section{Conclusions}

This modified JBT showed a high rate of procedural success and excellent SB protection during PCI of coronary bifurcation lesions. The treatment effect was good and there were no adverse events immediately after the procedure and during the 9-month follow-up.
MACE: Major adverse cardiac events; MI: Myocardial infarction; MV: Main vessel; OCT: Optical coherence tomography; PCl: Percutaneous coronary interventions; PD: Posterior descending artery; PL: Posterolateral artery; POT: Proximal optimization technique; RCA: Right coronary artery; SB: Side branch; TIMI: Thrombolysis in myocardial infarction; TLR: Target lesion revascularization; UFH: Unfractionated heparin

\section{Acknowledgments \\ Not applicable.}

Ethics approval and consent to paricipate

The study was approved by the Ethics Committee of Beijing hospital.

\section{Concent for publication}

Not applicable.

\section{Funding}

This study was supported by the Pilot Fund of Beijing Lisheng Cardiovascular Health Foundation (No. LHJJ20144210).

Availability of Data and materials

The data used to support the findings of this study are available from the corresponding author upon request.

\section{Author's contributions}

WZ conceived and coordinated the study, designed, performed and analyzed the experiments, wrote the paper. FJ, XY, XW carried out the data collection, data analysis, and revised the paper. All authors reviewed the results and approved the final version of the manuscript.

\section{Competing interests}

The authors declare that they have no competing interests.

\section{Publisher's Note}

Springer Nature remains neutral with regard to jurisdictional claims in published maps and institutional affiliations.

\footnotetext{
Abbreviations

ACS: Acute coronary syndromes; CCS: Canadian Cardiovascular Society; IVUS: Intravascular ultrasound; JBT: Jailed-balloon technique; LAD: Left anterior descending artery; LCX: Left circumflex artery; LM: Left main;
} 
Received: 14 August 2018 Accepted: 27 December 2018

Published online: 10 January 2019

\section{References}

1. Anderson JL, Adams CD, Antman EM, et al. ACC/AHA 2007 guidelines for the management of patients with unstable angina/non-ST-elevation myocardial infarction: a report of the American College of Cardiology/ American Heart Association task force on practice guidelines (writing committee to revise the 2002 guidelines for the Management of Patients with Unstable Angina/non-ST-elevation myocardial infarction) developed in collaboration with the American College of Emergency Physicians, the Society for Cardiovascular Angiography and Interventions, and the Society of Thoracic Surgeons endorsed by the American Association of Cardiovascular and Pulmonary Rehabilitation and the Society for Academic Emergency Medicine. J Am Coll Cardiol. 2007:50(7):e1-e157.

2. Braunwald E. Unstable angina and non-ST elevation myocardial infarction. Am J Respir Crit Care Med. 2012;185(9):924-32.

3. Park JE, Chiang CE, Munawar M, et al. Lipid-lowering treatment in hypercholesterolaemic patients: the CEPHEUS Pan-Asian survey. Eur J Prev Cardiol. 2012:19(4):781-94.

4. Khoo CM, Tan ML, Wu Y, et al. Prevalence and control of hypercholesterolaemia as defined by NCEP-ATPIII guidelines and predictors of LDL-C goal attainment in a multi-ethnic Asian population. Ann Acad Med Singapore. 2013;42(8):379-87.

5. Ohira T, Iso H. Cardiovascular disease epidemiology in Asia: an overview. Circ J. 2013;77(7):1646-52.

6. Chan MY, Du X, Eccleston D, et al. Acute coronary syndrome in the AsiaPacific region. Int J Cardiol. 2016;202:861-9.

7. Eshtehardi P, McDaniel MC, Suo J, et al. Association of coronary wall shear stress with atherosclerotic plaque burden, composition, and distribution in patients with coronary artery disease. J Am Heart Assoc. 2012;1(4):e002543.

8. Finch W, Lee MS. Percutaneous coronary intervention for coronary bifurcation lesions. Rev Cardiovasc Med. 2017:18(2):59-66.

9. van der Giessen AG, Wentzel JJ, Meijboom WB, et al. Plaque and shear stress distribution in human coronary bifurcations: a multislice computed tomography study. Eurolntervention. 2009;4(5):654-61.

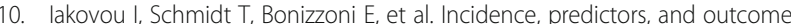
of thrombosis after successful implantation of drug-eluting stents. JAMA. 2005;293(17):2126-30.

11. Steigen TK, Maeng M, Wiseth $R$, et al. Randomized study on simple versus complex stenting of coronary artery bifurcation lesions: the Nordic bifurcation study. Circulation. 2006;114(18):1955-61.

12. Lee JM, Park KW, Koo BK, Kim HS. Stenting of coronary bifurcation lesions: a literature and technical review. Curr Cardiol Rep. 2015;17(6):45.

13. Latib A, Colombo A. Bifurcation disease: what do we know, what should we do? JACC Cardiovasc Interv. 2008:1(3):218-26.

14. Genereux P, Kumsars I, Lesiak M, et al. A randomized trial of a dedicated bifurcation stent versus provisional stenting in the treatment of coronary bifurcation lesions. J Am Coll Cardiol. 2015;65(6):533-43.

15. Abdel-Latif A, Moliterno DJ. Bifurcation stenting techniques and outcomes in patients with stable coronary artery disease: more evidence suggesting simpler is safer. JACC Cardiovasc Interv. 2015;8(4):561-3.

16. Lassen JF, Holm NR, Stankovic G, et al. Percutaneous coronary intervention for coronary bifurcation disease: consensus from the first 10 years of the European bifurcation Club meetings. Eurolntervention. 2014;10(5):545-60.

17. Brar SS, Gray WA, Dangas G, et al. Bifurcation stenting with drug-eluting stents: a systematic review and meta-analysis of randomised trials. Eurolntervention. 2009;5(4):475-84.

18. Singh J, Patel $Y$, Depta JP, et al. A modified provisional stenting approach to coronary bifurcation lesions: clinical application of the "jailed-balloon technique". J Interv Cardiol. 2012;25(3):289-96.

19. Burzotta F, Trani C, Sianos G. Jailed balloon protection: a new technique to avoid acute side-branch occlusion during provisional stenting of bifurcated lesions. Bench test report and first clinical experience. Eurolntervention. 2010;5(7):809-13.

20. Medina A, Suarez de Lezo J, Pan M. A new classification of coronary bifurcation lesions. Rev Esp Cardiol. 2006;59(2):183.

21. Colombo A, Bramucci E, Sacca S, et al. Randomized study of the crush technique versus provisional side-branch stenting in true coronary bifurcations: the CACTUS (coronary bifurcations: application of the crushing technique using Sirolimus-eluting stents) study. Circulation. 2009;119(1):71-8.
22. Silber S, Albertsson P, Aviles FF, et al. Guidelines for percutaneous coronary interventions. The task force for percutaneous coronary interventions of the European Society of Cardiology. Eur Heart J. 2005;26(8):804-47.

23. Cutlip DE, Windecker $\mathrm{S}$, Mehran $\mathrm{R}$, et al. Clinical end points in coronary stent trials: a case for standardized definitions. Circulation. 2007;115(17):2344-51.

24. Zhang $D, X u B$, Yin D, et al. Predictors and Periprocedural myocardial injury rate of small side branches occlusion in coronary bifurcation intervention. Medicine (Baltimore). 2015;94(25):e992.

25. Campeau L. Letter: grading of angina pectoris. Circulation. 1976;54(3):522-3.

26. Depta JP, Patel Y, Patel JS, et al. Long-term clinical outcomes with the use of a modified provisional jailed-balloon stenting technique for the treatment of nonleft main coronary bifurcation lesions. Catheter Cardiovasc Interv. 2013;82(5):E637-46.

27. Louvard $Y$, Lefevre T, Morice MC. Percutaneous coronary intervention for bifurcation coronary disease. Heart. 2004:90(6):713-22.

28. Owens CG, Spence MS. How should I treat a patient to remove a fractured jailed side branch wire? Eurolntervention. 2011;7(4):520-7.

29. Kang SJ, Mintz GS, Kim WJ, et al. Preintervention angiographic and intravascular ultrasound predictors for side branch compromise after a single-stent crossover technique. Am J Cardiol. 2011;107(12):1787-93.

30. Brunel P, Lefevre T, Darremont O, Louvard Y. Provisional T-stenting and kissing balloon in the treatment of coronary bifurcation lesions: results of the French multicenter "TULIPE" study. Catheter Cardiovasc Interv. 2006; 68(1):67-73.

31. Cayli M, Seker T, Gur M, et al. A novel-modified provisional bifurcation stenting technique: jailed semi-inflated balloon technique. J Interv Cardiol. 2015;28(5):420-9.

32. Saito S, Shishido K, Moriyama N, et al. Modified jailed balloon technique for bifurcation lesions. Catheter Cardiovasc Interv. 2018;2(3):E218-26.

\section{Ready to submit your research? Choose BMC and benefit from:}

- fast, convenient online submission

- thorough peer review by experienced researchers in your field

- rapid publication on acceptance

- support for research data, including large and complex data types

- gold Open Access which fosters wider collaboration and increased citations

- maximum visibility for your research: over $100 \mathrm{M}$ website views per year

At BMC, research is always in progress.

Learn more biomedcentral.com/submission 